\title{
Bioremediation of Oil Contaminated Soils by Washing under Static Conditions
}

\author{
Z. Ghorbani Kharaji ${ }^{1}$, M. H. Fazaelipoor ${ }^{2 *}$ \\ ${ }^{1}$ Department of Chemical Engineering, Faculty of Engineering, Shahid Bahonar University of Kerman, Kerman, Iran \\ ${ }^{2}$ Department of Chemical and polymer Engineering, Faculty of Engineering, Yazd University, Yazd, Iran
}

\section{$P A P E R \quad I N F O$}

\section{Paper history:}

Received 17 September 2019

Accepted in revised form 24 November 2019

\section{Keywords:}

Bioremediation

Soil

Static Conditions

Sucrose

Surfactant

\section{$A B S T R \quad R A C T$}

In this research five different solutions were used to wash an oil contaminated soil with the initial TPH (Total Petroleum Hydrocarbon) content of $46 \mathrm{~g} \mathrm{~kg}^{-1}$ (grams of TPH per kg of dry soil). The solutions were a basal mineral medium (solution I), the basal mineral medium inoculated with petroleum degrading microorganisms (solution II), the basal mineral medium inoculated with a culture of petroleum degrading microorganisms and supplemented with a commercial washing powder (solution III), the basal mineral medium inoculated with the microorganisms and supplemented with Tween 80 (solution IV), and the basal mineral medium inoculated with the microorganisms and supplemented with sucrose (Solution V). Washing was performed by saturation of the soil with the solutions in columns and intermittent mixing. Solutions IV and V performed better than the others, giving more than $90 \%$ TPH removal in two months. In a separate experiment TPH removal was monitored as a function of time during washing. Solution V reduced the TPH content of the soil more rapidly than the others, with more than $70 \%$ TPH removal in 28 days. Addition of sand particles to the soil for the purpose of better mixing resulted in marginal positive effects.

\section{INTRODUCTION}

Contamination of soil with hydrocarbons is a common problem during exploration, recovery, transportation, and utilization of oil. Remediation of soil is necessary due to the adverse effects of hydrocarbons on ecosystems. Various physical, chemical, and biological methods have been developed for soil remediation [1]. In bioremediation, naturally occurring microorganisms are applied to degrade oil contaminants. Compared to physical and chemical methods, bioremediation has several advantages such as being less expensive and more environmental friendly. Bioremediation, however, suffers from the disadvantage of being slow compared to physical and chemical methods. Bebskoski et al. [2] reported more than five months to reduce the TPH content of a soil from $5.2 \mathrm{~g} \mathrm{~kg}^{-1}$ to $0.3 \mathrm{~g} \mathrm{~kg}^{-1}$, despite microbial and nutrient addition to the soil and systematic mixing to facilitate oxygen transfer. Acceleration of bioremediation, therefore, needs ways beyond nutrient $(\mathrm{N}, \mathrm{P}, \mathrm{K})$ addition and/or microbial inoculation.

Various chemicals have been tested for their beneficial effects on bioremediation. Addition of surfactants to polluted soils is supposed to help desorption of hydrophobic components from soil matrices due to their amphipatic nature.
Uhmann and Aspray [3] examined SP 101 (a biosurfactant) and Tween 80 in soil washing and proved the significant effect of the surfactants in removing TPH content of soil. In particular, they showed that the effectiveness of surfactants on the removal of TPH from each fraction of the tested soil was different from the other fractions [3]. Menedez-Vega et al. [4] injected hydrogen peroxide (to provide oxygen), an oleophilic fertilizer (to provide nutrients), and a commercial biodegradable surfactant (to facilitate hydrocarbon desorption) to subsurface soils to boost hydrocarbon biodegradation. They concluded that the conventional methods of nutrient addition are inadequate for effective soil bioremediation, and the methods should be complemented by providing oxygen and a surfactant to the soil [4]. Mixing polluted soil (10 $\mathrm{g} \mathrm{kg}^{-1}$ of TPH content) with sewage sludge and compost was the idea tested by Namkoong et al. [5]. The results revealed that the addition of sewage sludge and compost each could increase the removal percentage of TPH in soil up to $98 \%$ compared to $65 \%$ removal for the control soil with no sewage sludge or compost amendments, in 30 days. Soleimani et al. [6] compared the effect of microbial enrichment, molasses, hydrogen peroxide, and nutrients on the bioremediation of TPH from soil. They found that nutrient addition gave the best results with $62 \%$ removal of the initial 
TPH content. However, Soleimani et al. [6] did not investigate the complementary effects of the amendments. Addition of a surfactants, hydrogen peroxide, and molasses to soil, without mineral nutrient provision would have little effect on bioremediation because microbes need a balanced medium in terms of carbon and mineral nutrients to grow well. Our objective in this research is to examine the effect of nutrients, nutrients plus sucrose, and nutrient plus Tween 80 on the bioremediation of hydrocarbons form a polluted soil.

\section{MATERIALS AND METHODS}

Soil

Hydrocarbon contaminated soil was collected from a gas oil distribution center. The soil was sieved to separate sand and coarse particles. The soil, then, was spread on the floor for more than one month to ensure complete vaporization of light hydrocarbons. After vaporization of light hydrocarbons, the soil was blended thoroughly, and its TPH content was measured $\left(46 \mathrm{~g} \mathrm{~kg}^{-1}\right)$.

\section{Microorganisms}

A group of unidentified petroleum degrading microorganisms were used in this research. The microorganisms were isolated from a petroleum contaminated soil, previously undergone a bioremediation process. The soil was suspended in water, and the suspension was filtered through a piece of cloth. $1 \mathrm{ml}$ of the resulting filtrate was added to a flask containing $250 \mathrm{ml}$ of a basal mineral medium (described below) and $1 \mathrm{ml}$ gas oil as the source of carbon and energy. The flask was incubated at $30{ }^{\circ} \mathrm{C}$. Microscopic inspection showed microbial growth in the flask. A few milliliters of this microbial solution was used as the inoculums to the washing solutions.

\section{Washing solutions}

Five different solutions were examined in this research. Solution I: a basal mineral medium with the composition listed in Table 1. Solution II: the basal mineral medium inoculated with the petroleum degrading microorganisms. Solution III: the basal mineral medium inoculated with the microorganisms and supplemented with a commercial washing powder $\left(5 \mathrm{~g} \mathrm{l}^{-1}\right)$. Solution IV: the basal mineral medium inoculated with the microorganisms and supplemented with Tween $80(1 \mathrm{v} \%)$. Solution V: the basal mineral medium inoculated with the microorganisms and supplemented with sucrose $\left(5 \mathrm{~g} \mathrm{l}^{-1}\right)$.

\section{Soil washing}

Ten identical columns with the height of $30 \mathrm{~cm}$ and the diameter of $5 \mathrm{~cm}$ were used for soil washing. Each column was filled with $800 \mathrm{~g}$ of the contaminated soil, and saturated with one of the solutions mentioned above (two replicates for each solution). Two more columns were used to investigate the usefulness of mixing sand particles with the polluted soil. These two columns were packed with a mixture of $400 \mathrm{~g}$ polluted soil and $400 \mathrm{~g}$ clean sand particles with the average diameter of $2 \mathrm{~mm}$. These two columns were saturated with solution II. The process continued for 60 days. During the process the contents of all columns were agitated manually using a metal bar every two days, and fresh solutions were added to compensate for water evaporation. After termination of the process, samples were taken from the columns, air dried to constant weights, and extracted to quantify their residual oil contents. In a separate experiment the changes in TPH contents of the soils washed with solutions II, IV, and V were quantified as a function of time. The process was the same as above, but it continued for one month, and the residual oil in the soil was quantified on a weekly basis.

\section{Analysis}

Soxhelt apparatus was used to extract the TPH content of the soil samples. Chloroform was used as the extractant. The TPH content was quantified gravimetrically [7].

\section{RESULTS AND DISCUSSIONS \\ The effect of washing solution on the bioremediation}

Soil bioremediation is a natural process and occurs very slowly if not stimulated. The slow rate of bioremediation is caused by several factors. Insufficient moisture, low population of degrading microorganisms, low bioavailability of the pollutants due to inadequate mixing and/or strong adsorption of pollutants to soil particles, and insufficient nutrients are among the factors which make the process slow. In this part five different solutions were compared in term of their effectiveness in TPH removal from soil. Figure 1 shows the results. Solution V gave the best results (more than 93\% removal). The solution contained mineral nutrients, sucrose, and TPH degrading microorganisms. Sucrose can be readily assimilated by most microorganisms. In the presence of mineral nutrients and this ready substrate, microbes could proliferate rapidly. Upon exhaustion of sucrose, the large population of microorganisms had to consume hydrocarbons is soil. Supplementation of washing solutions; therefore, with a readily available substrate can enhance the rate of soil bioremediation considerably. Washing the soil with solution IV gave comparable result with the result of washing with solution V (more than $90 \%$ removal). Solution IV contained mineral nutrients, Tween 80, and TPH degrading microorganisms. Tween 80 can disperse hydrophobic oil components in aqueous phase and make them readily available to microorganisms. Other solutions were less effective than solutions IV and V. Washing the polluted soil

TABLE 1. Composition of the basal mineral medium used in soil washing

\begin{tabular}{lcccccc}
\hline Compound & $\mathbf{C a C l}_{\mathbf{2}} \mathbf{7} \mathbf{H}_{\mathbf{2}} \mathbf{O}$ & $\mathbf{M g C l}_{\mathbf{2}} \mathbf{7} \mathbf{H}_{\mathbf{2}} \mathbf{O}$ & $\mathbf{K}_{\mathbf{2}} \mathbf{H P O}_{\mathbf{4}}$ & $\mathbf{K H}_{\mathbf{2}} \mathbf{P O}_{\mathbf{4}}$ & $\mathbf{N H}_{\mathbf{4}} \mathbf{S O}_{\mathbf{4}}$ & $\mathbf{F e S O}_{\mathbf{4}}$ \\
\hline Concentration $\left(\mathrm{g} \mathrm{l}^{-1}\right)$ & 0.04 & 0.2 & 4.3 & 3.4 & 4 & 0.03 \\
Compound & $\mathrm{MnCl}_{2}$ & $\mathrm{NaMoO}_{4}$ & $\mathrm{CuSO}_{4}$ & $\mathrm{H}_{3} \mathrm{BO}_{3}$ & $\mathrm{ZnSO}_{4}$ & 0.0017 \\
Concentration $\left(\mathrm{g} \mathrm{l}^{-1}\right)$ & 0.001 & 0.00175 & 0.00015 & 0.000375 & \\
\hline
\end{tabular}




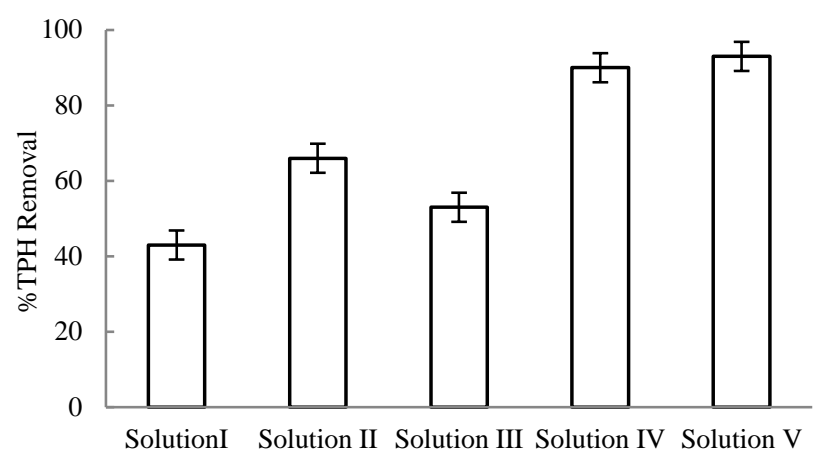

Figure 1. TPH removal in soil, washing with different solutions; The solutions have been defined in Materials and Methods. Initial TPH content and process duration were $46 \mathrm{~g} \mathrm{~kg}^{-1}$ and 60 days, respectively.

with solution II resulted in $66 \%$ removal of TPH from soil in 2 months. The solution contained mineral nutrients and petroleum degrading microorganisms. Solution III, which was different from solution II only in having a commercial washing powder, was less effective than solution II (53\% removal). Though containing some surfactants, washing powders normally contain a number of other substances, some of which harmful to microbial activity. So, washing powders might not be a proper additive to washing solutions for oil polluted soils. The lowest removal was for solution I (43\% removal). The solution contained only mineral nutrients. Overall the results of this part showed that addition of microorganisms, surfactants, and a simple sugar such as sucrose can accelerate the rate of soil bioremediation considerably.

\section{The effect of sand particles on the bioremediation}

The purpose of mixing the polluted soil with sand particles was to enhance mixing efficiency and oxygen transfer in the soil, and to reduce soil compaction during the process. Figure 2 shows the results. The removal percentage in the sand containing column reached $74 \%$, compared to its sand free counterpart with $66 \%$ removal (Sand particles were removed from the soil after termination of the process and before quantifying the residual oil.). Application of sand had marginal effects on the efficiency of bioremediation. Sand particles are biologically inert, and the roles could be supposed for them in bioremediation were their usefulness in better mixing and reducing soil compaction. Since mixing of the soil in columns was done on a regular basis, and soil compaction was not a problem in this work due to the rather small size of the columns, the difference in performances was not very large.

\section{Soil bioremediation as a function of time}

The performances of solutions II, IV, and V were monitored as a function of time. Figure 3 shows the results for solution II. On day 28, $32 \%$ of the TPH was removed from the soil. Figures 4 and 5 show that while the TPH removal for solution $\mathrm{V}$ was greater than $70 \%$ in 28 days, the removal was only $49 \%$ for solution IV during the same period of time. The results confirm that the inclusion of a simple sugar in the washing solution can accelerate bioremediation more rapidly than Tween 80. In addition to being less effective than sucrose,

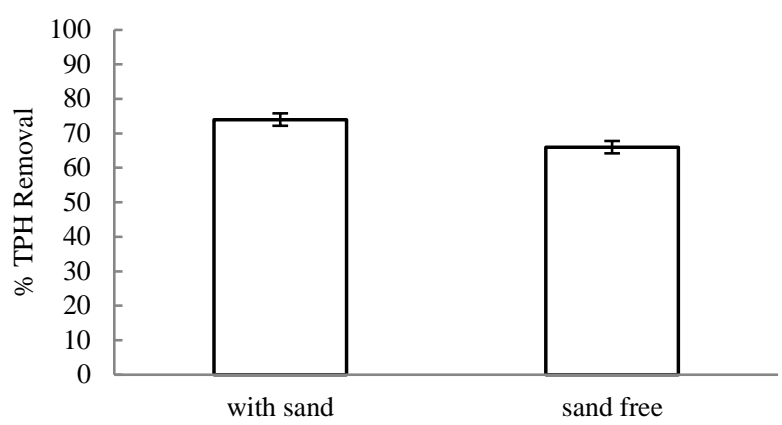

Figure 2. The effect of sand particles on the removal of TPH from soil; Solution II was used for washing. The solution has been defined in Materials and Methods. Initial TPH content and process duration were $46 \mathrm{~g} \mathrm{~kg}^{-1}$ and 60 days, respectively.

Tween 80 , as a synthetic surfactant, suffers from another disadvantage. Synthetic surfactants are normally nonbiodegradable and may remain in soil very long.

Acceleration of bioremediation is the main advantage of the method offered in this work, compared to similar works reported in the literature. In general, most works on bioremediation have reported rather a long time to achieve high percentages of TPH removal in soil. For example, Milic et al. [8] reported 5.5 months to achieve 90\% TPH removal from a soil having the initial TPH content of $28.8 \mathrm{~g} \mathrm{~kg}^{-1}$. Poultry manure was supplemented to provide $\mathrm{N}$ and $\mathrm{P}$ to the indigenous microorganisms in the soil. The soil was aerated using a perforated pipe. Microbiological studies showed the presence of TPH degraders in the soil. Despite the provision of favorable conditions for microbial growth, it took rather a long time to achieve $90 \%$ removal of TPH [8]. In a similar work Gogoi et al. [9] reported up to $75 \%$ removal of TPH for soil during the period of 1 year. Laboratory and field tests gave similar results. Aeration, nutrient provision, and external inoculation of TPH degraders were applied to enhance bioremediation. The initial TPH content of the soil was 13.35 $\mathrm{wt} \%$ on dry basis, and the moisture content was adjusted between 10 to $15 \%$ [9]. Low initial microbial population and inadequate moisture content could be the reasons for the slow rate of the bioremediation process in the mentioned works. Rapid proliferation of the microorganisms due to the presence of sucrose in the washing solution can be a reason for acceleration of the bioremediation process.

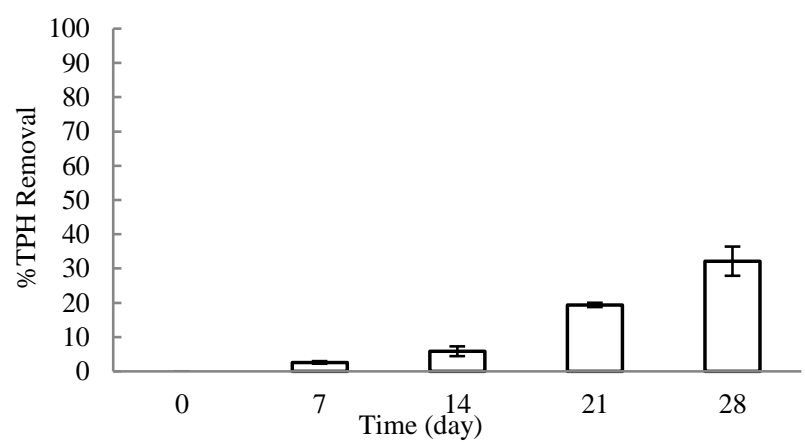

Figure 3. TPH removal from soil as a function of time washing with solution II. The solution has been defined in Materials and Methods. Initial TPH content and process duration were $46 \mathrm{~g} \mathrm{~kg}^{-1}$ and 60 days, respectively. 


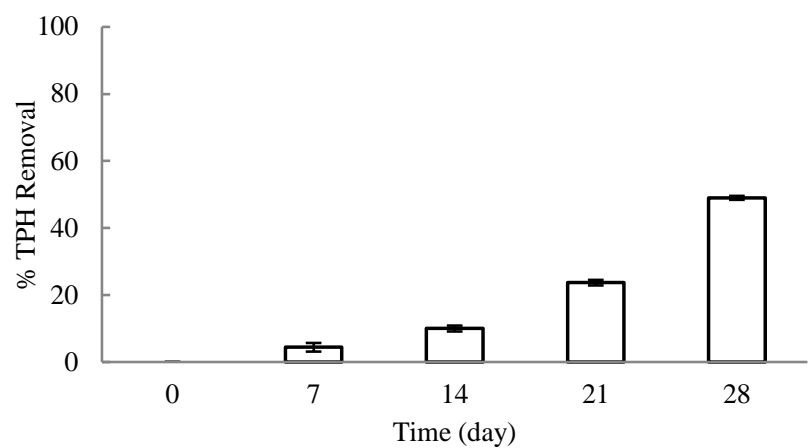

Figure 4. TPH removal from soil as a function of time washing with solution IV. The solution has been defined in Materials and Methods. Initial TPH content and process duration were $46 \mathrm{~g} \mathrm{~kg}^{-1}$ and 60 days, respectively.

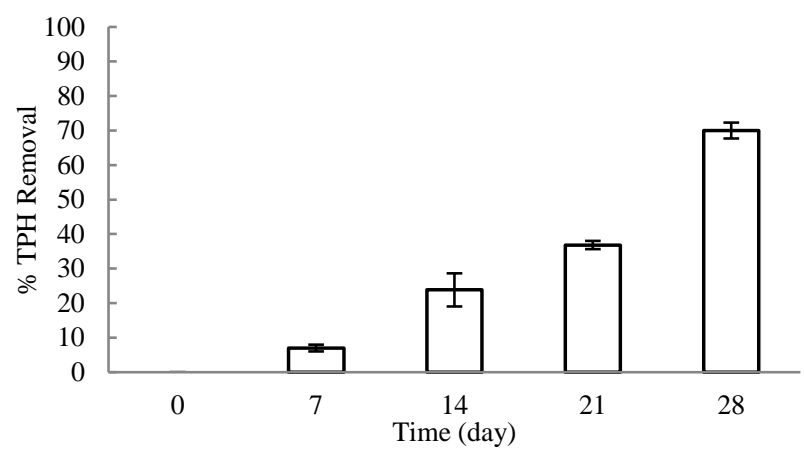

Figure 5. TPH removal from soil as a function of time washing with solution V. The solution has been defined in Materials and Methods. Initial TPH content and process duration were $46 \mathrm{~g} \mathrm{~kg}^{-1}$ and 60 days, respectively.

As mentioned in the introduction part, Namkoong et al. [5] blended sewage sludge and compost with the polluted soil and achieved $98 \%$ removal of TPH in 30 days. The relative short period of bioremediation in their work can be explained by the high population of microorganisms in the sludge and compost.

\section{CONCLUSION}

Saturation of polluted soil with a washing solution and intermittent mixing is an efficient way for the removal of hydrocarbons from soil. Inclusion of minerals, microorganisms, and sucrose in the washing solution accelerates the bioremediation process considerably. Inclusion of Tween 80, instead of sucrose, is also useful in the bioremediation process, but the process is slower. Sucrose as a readily accessible substrate is supposedly helps rapid proliferation of microorganisms. The microorganisms attack hydrocarbons upon exhaustion of sucrose. Further research work is needed to optimize the amount of sucrose in the washing solution, and to implement the method to larger scales.

\section{REFERENCES}

1. Fox, R.D., 1996. Physical/chemical treatment of organically contaminated soils and sediments. Journal of the Air \& Waste Management Association, 46(5), pp.391-413.

2. Beškoski, V.P., Gojgić-Cvijović, G., Milić, J., Ilić, M., Miletić, S. Šolević, T. and Vrvić, M.M., 2011. Ex situ bioremediation of a soil contaminated by mazut (heavy residual fuel oil)-A field experiment. Chemosphere, 83(1), pp.34-40.

3. Uhmann, A. and Aspray, T.J., 2012. Potential benefit of surfactants in a hydrocarbon contaminated soil washing process: Fluorescence spectroscopy based assessment. Journal of hazardous materials, 219 pp.141-147.

4. Menendez-Vega, D., Gallego, J.L.R., Pelaez, A.I., de Cordoba, G.F., Moreno, J., Munoz, D. and Sanchez, J., 2007. Engineered in situ bioremediation of soil and groundwater polluted with weathered hydrocarbons. European Journal of Soil Biology, 43(5-6), pp.310321.

5. Namkoong, W., Hwang, E.Y., Park, J.S. and Choi, J.Y., 2002. Bioremediation of diesel-contaminated soil with composting. Environmental pollution, 119(1), pp.23-31.

6. Soleimani, M., Farhoudi, M. and Christensen, J.H., 2013. Chemometric assessment of enhanced bioremediation of oil contaminated soils. Journal of hazardous materials, 254, pp.372-381.

7. Chemlal, R., Tassist, A., Drouiche, M., Lounici, H., Drouiche, N. and Mameri, N., 2012. Microbiological aspects study of bioremediation of diesel-contaminated soils by biopile technique. International biodeterioration \& biodegradation, 75, pp.201-206.

8. Milić, J., Beškoski, V., Ilić, M., Ali, S.A., Gojgić Cvijović, G. and Vrvić, M., 2009. Bioremediation of soil heavily contaminated with crude oil and its products: composition of the microbial consortium. Journal of the Serbian Chemical Society, 74(4), pp.455460 .

9. Gogoi, B.K., Dutta, N.N., Goswami, P. and Mohan, T.K., 2003. A case study of bioremediation of petroleum-hydrocarbon contaminated soil at a crude oil spill site. Advances in Environmental Research, 7(4), pp.767-782.

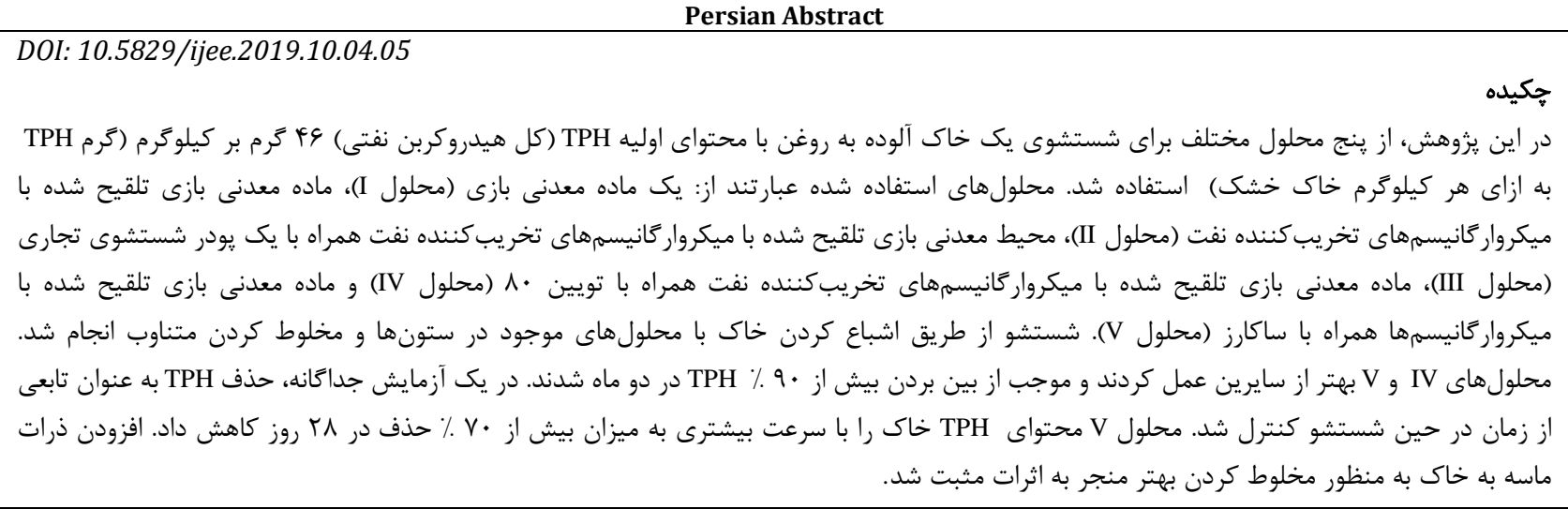

